\title{
Incidence and Management of Aflatoxin Contamination in Groundnut (Arachis hypogaea L.) in Northern Ghana
}

\author{
Paul B. Tanzubil* and Iddrisu Adam
}

International Crops Research Institute for the Semi-Arid Tropics (ICRISAT), Tamale, Ghana

*Corresponding author:

\section{A B S T R A C T}

\section{Keywords}

Aflatoxin, Arachis

hypogaea,

Groundnut,

Aspergillus

Article Info

Accepted:

12 January 2019

Available Online:

10 February 2019

\begin{abstract}
Aflatoxin contamination levels were monitored in groundnut products derived from participatory on-farm demonstration plots, farm stores and markets in 21 districts in Northern Ghana in 2015 and 2016. Results clearly showed that improved production technology (variety + agronomic practises) significantly reduced aflatoxin contamination and increased kernel yield. Though no clear and consistent trend of varietal differences in aflatoxin contamination could be established from the studies over the two years across locations, NkatieSari showed the least mean contamination (2.74 ppb and $2.39 \mathrm{ppb})$ while SAMNUT 22 had the highest levels of contamination (7.51 ppb and $3.31 \mathrm{ppb})$ in 2015 and 2016 respectively. Most groundnut products sampled from households and markets, had aflatoxin levels higher than the EU acceptable limit of $4 \mathrm{ppb}$ and this calls for more intensive sensitization of value chain actors, especially the processors, and rigorous monitoring of groundnut products to minimize the risks of human and livestock poisoning from aflatoxin contamination.
\end{abstract}

\section{Introduction}

Groundnut (Arachis hypogaea L.) is the most important food legume crop in Ghana in terms of area of cultivation and utilization, contributing significantly towards food and nutrition security, especially among the rural poor (Awuah, 2000). The bulk of groundnut production in Ghana about $85 \%$ of the groundnut production takes place in the northern Guinea and Sudan Savanna zones but yields are marginally low, usually less than $1 \mathrm{t} / \mathrm{ha}$ compared with the potential of 2.5t/ha (Tsigbey et al., 2003; Angelucci et al.,
2013). Poor access to improved varieties and quality seed, poor soils and a high incidence of pests and diseases account for the low levels of productivity (Tsigbey et al., 2003; Tanzubil, 2016). The harvested crop is also widely contaminated by aflatoxins but the extent of the problem remains poorly documented and appreciated, inspite of many reported cases of its adverse economic, health and nutritional consequences especially among rural communities.

Ingestion of high doses of aflatoxin often lead to acute aflatoxicoses and death, while 
smaller doses over time predispose victims to a range of health problems including stunting liver cancer, cirrhosis and hepatitis (William et al., 2013). The USAID-funded Groundnut Technology Scaling Project, being implemented in Northern Ghana by ICRISAT and local partners, is creating greater awareness about aflatoxin and its management using participatory field demonstrations, sensitization and training of value chain actors.

The activities described in this paper were undertaken to:

Improve farmers' knowledge of, and access to improved groundnut technologies on aflatoxin and its management through participatory onfarm demonstrations and training

Assess the effect of project demonstrations on improved groundnut technologies on aflatoxin contamination of groundnut produced by farmers.

Assess the levels of aflatoxin contamination in key groundnut products across the value chain.

\section{Materials and Methods}

Farmer participatory demonstrations on improved groundnut production and aflatoxin management technologies

Participatory demonstrations on improved groundnut production technology (varieties, agronomic practises) were conducted by the various project partners from 2015 to 2017, using $10 \mathrm{~m} \mathrm{X} 10 \mathrm{~m}$ on farmer fields in the 21 project districts in Northern Ghana. Each demonstration compared 3 improved varieties (Yenyawaso, NkatieSari and Samnut 22) + improved agronomic practices with the Farmer variety and crop management. A minimum of 140 such demonstrations were mounted annually using new farmer groups each time. The demonstration plots were also used for farmer field days, farmer training, farmer exchange visits and other project activities. Pod samples $(1 \mathrm{~kg})$ were collected from each plot at harvest, dried and later analysed for aflatoxin contamination using the Aflatoxin Mobil Assay (mReader) which employs Reveal Q+ test strips (Neogen Corperation).

\section{Monitoring aflatoxin contamination of groundnut products in the value chain}

Samples of groundnut products were collected annually between November and January of 2015 and 2016 from various sources in the 21 project districts. Pod samples (P) were collected from farmers' stores while kernels (K) and groundnut paste (GP) were sampled from local markets in the study districts. A minimum of 15 samples of each product was collected per district annually and analysed for aflatoxin contamination as described in 2.1 above. Results from the analysis and their implications were shared with value chain actors and policy makers using community fairs, review meetings, school visits, trainings and radio broadcasts. [

\section{Results and Discussion}

\section{Aflatoxin levels in harvests from demonstration plots}

Pod samples derived from 2015 demonstration plots had aflatoxin levels ranging from 1.46 to $19.72 \mathrm{ppb}$ with a grand mean of $6.51 \mathrm{ppb}$. In 2016, aflatoxin levels were generally lower with a grand mean of $3.95 \mathrm{ppb}$ and a range of $1.01 \mathrm{ppb}$ to $13.59 \mathrm{ppb}$ (Table 1). This is an indication that the project demonstrations of introducing improved varieties and agronomic practices to farmers had the desired effect of reducing aflatoxin contamination. 
All the improved varieties/agronomic practices plots showed lower levels of aflatoxin contamination than the farmers' variety/practice. Among the improved varieties however, no clear and consistent trend of varietal differences in aflatoxin contamination could be established from the studies over the two years across locations. Overall, Nkatie Sari showed the least mean contamination of $2.74 \mathrm{ppb}$ and $2.39 \mathrm{ppb}$ while SAMNUT 22 had the highest levels of contamination of $7.51 \mathrm{ppb}$ and $3.31 \mathrm{ppb}$ in 2015 and 2016 respectively. As shown in Table 2, there were no significant differences in yield among the improved technology treatments but they all gave significantly higher kernel yields than the farmer practice in both years.

The results also showed that samples from demonstration plots in the UER had significantly lower aflatoxin contamination than those from the NR and UWR. Aflatoxin contamination is known to be favoured by high Relative Humidity which promotes the proliferation of the causal fungus Aspergillus spp (Waliyar et al., 2015). The observed differences in our study might therefore be due to the known differences in climatic conditions among the regions as UER (Sudan savannah) usually has with lower rainfall and $\mathrm{RH}$ than the NR and UWR which are largely situated in the Guinea savanna.

\section{Aflatoxin levels in different groundnut products}

Groundnut pastes had the highest levels of aflatoxin contamination $(30-55 \mathrm{ppb})$ across regions, followed by the kernels $(3-34 \mathrm{ppb})$ and pods $(2.8-27 \mathrm{ppb})$ in that order. This trend was generally the same for products within and across regions over the two years of the study (Figs. 1 and 2).

\section{Table.1 Aflatoxin contamination levels ( $\mathrm{ppb}$ ) in kernels from demonstration plots (2015 and 2016)}

\begin{tabular}{|l|l|l|l|l|l|l|l|l|}
\hline & \multicolumn{9}{|c|}{$\mathbf{2 0 1 5}$} & \multicolumn{4}{c|}{$\mathbf{2 0 1 6}$} \\
\hline Variety & UER & NR & UW & Mean & UER & NR & UW & Mean \\
\hline Yenyawoso & 1.66 & $12.63 b$ & 1.61 & $\mathbf{5 . 3 0}$ & 2.06 & 1.56 & 5.17 & $\mathbf{2 . 9 3}$ \\
\hline Nkatiesari & 1.70 & 1.53 & 5.00 & $\mathbf{2 . 7 4}$ & 1.63 & 1.61 & 3.94 & $\mathbf{2 . 3 9}$ \\
\hline Samnutt 22 & 1.46 & $17.45 \mathrm{a}$ & 3.63 & $\mathbf{7 . 5 1}$ & 1.46 & 1.59 & 6.91 & $\mathbf{3 . 3 1}$ \\
\hline Farmer variety & 1.69 & $10.08 \mathrm{~b}$ & 19.72 & $\mathbf{1 0 . 3 0}$ & 1.01 & 6.91 & 13.59 & $\mathbf{7 . 1 7}$ \\
\hline Mean & $\mathbf{1 . 6 2}$ & $\mathbf{1 0 . 4 2}$ & $\mathbf{7 . 4 9}$ & $\mathbf{6 . 5 1}$ & $\mathbf{1 . 5 4}$ & $\mathbf{2 . 9 1}$ & $\mathbf{7 . 4 0}$ & $\mathbf{3 . 9 5}$ \\
\hline LSD & 0.56 & 3.42 & 2,96 & & 0.74 & 0.96 & 3.21 & \\
\hline
\end{tabular}

Table.2 Kernel Yield (kg/ha) from demonstration plots in 2015, 2016

\begin{tabular}{|l|l|l|l|l|l|l|l|l|}
\hline & \multicolumn{9}{|c}{$\mathbf{2 0 1 5}$} & \multicolumn{4}{c|}{ 2016 } \\
\hline Variety & UER & NR & UW & Mean & UER & NR & UW & Mean \\
\hline Yenyawoso & 1153 & 1170 & 1040 & $\mathbf{1 1 2 0}$ & 1000 & 1293 & 780 & $\mathbf{1 0 2 4}$ \\
\hline Nkatiesari & 1102 & 1176 & 1103 & $\mathbf{1 1 3 0}$ & 912 & 1200 & 1140 & $\mathbf{1 0 8 4}$ \\
\hline Samnutt 22 & 1217 & 1420 & 1092 & $\mathbf{1 2 4 3}$ & 1200 & 1216 & 1012 & $\mathbf{1 1 4 2}$ \\
\hline Farmer variety & 805 & 931 & 864 & $\mathbf{8 6 7}$ & 878 & 938 & 798 & $\mathbf{8 7 1}$ \\
\hline Mean & $\mathbf{1 0 6 9}$ & $\mathbf{1 1 7 4}$ & $\mathbf{1 0 2 5}$ & $\mathbf{1 0 9 0}$ & $\mathbf{9 9 8}$ & $\mathbf{1 1 6 1}$ & $\mathbf{9 3 3}$ & $\mathbf{1 0 3 0}$ \\
\hline LSD & & & & $\mathbf{2 4 0}$ & & & & $\mathbf{1 8 5}$ \\
\hline
\end{tabular}


Fig.1

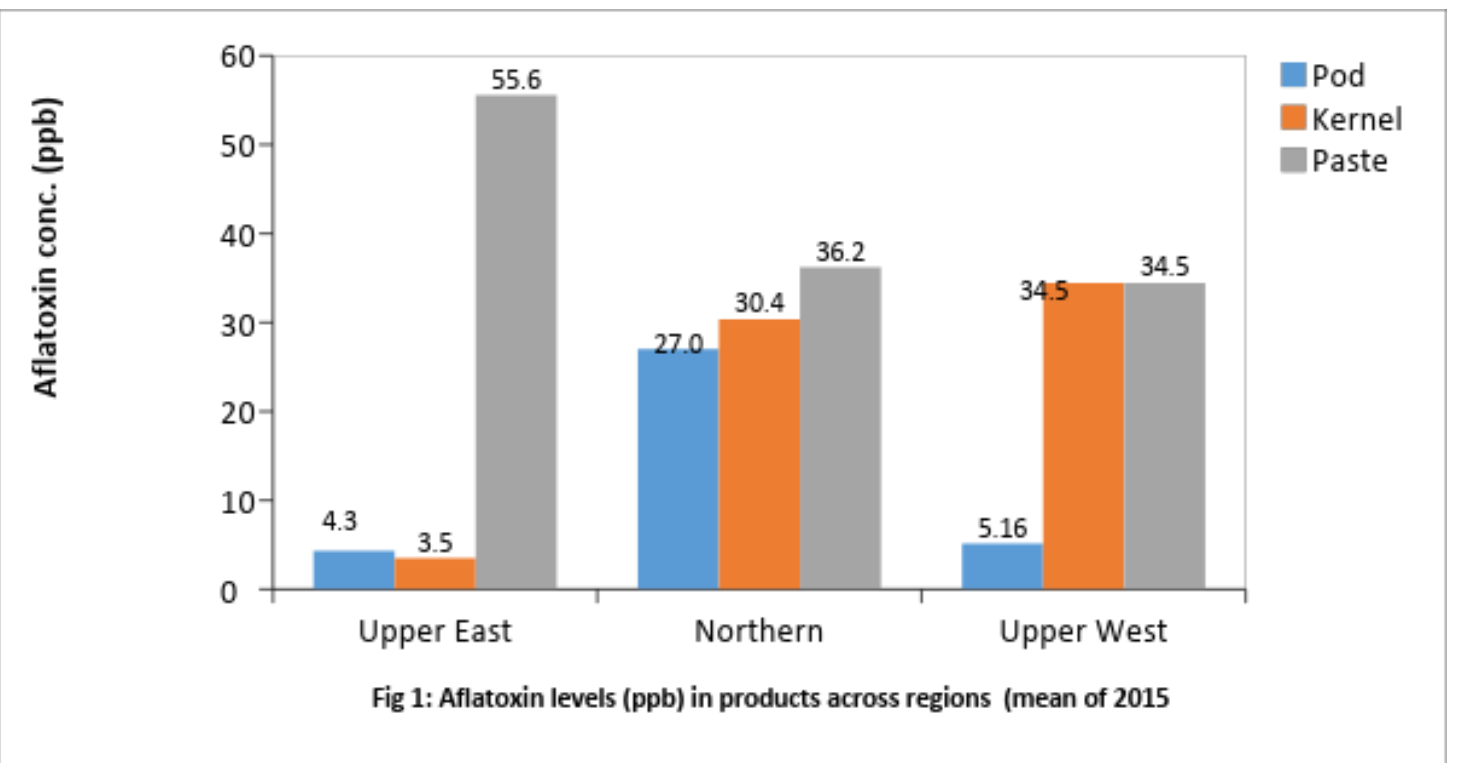

Fig.2

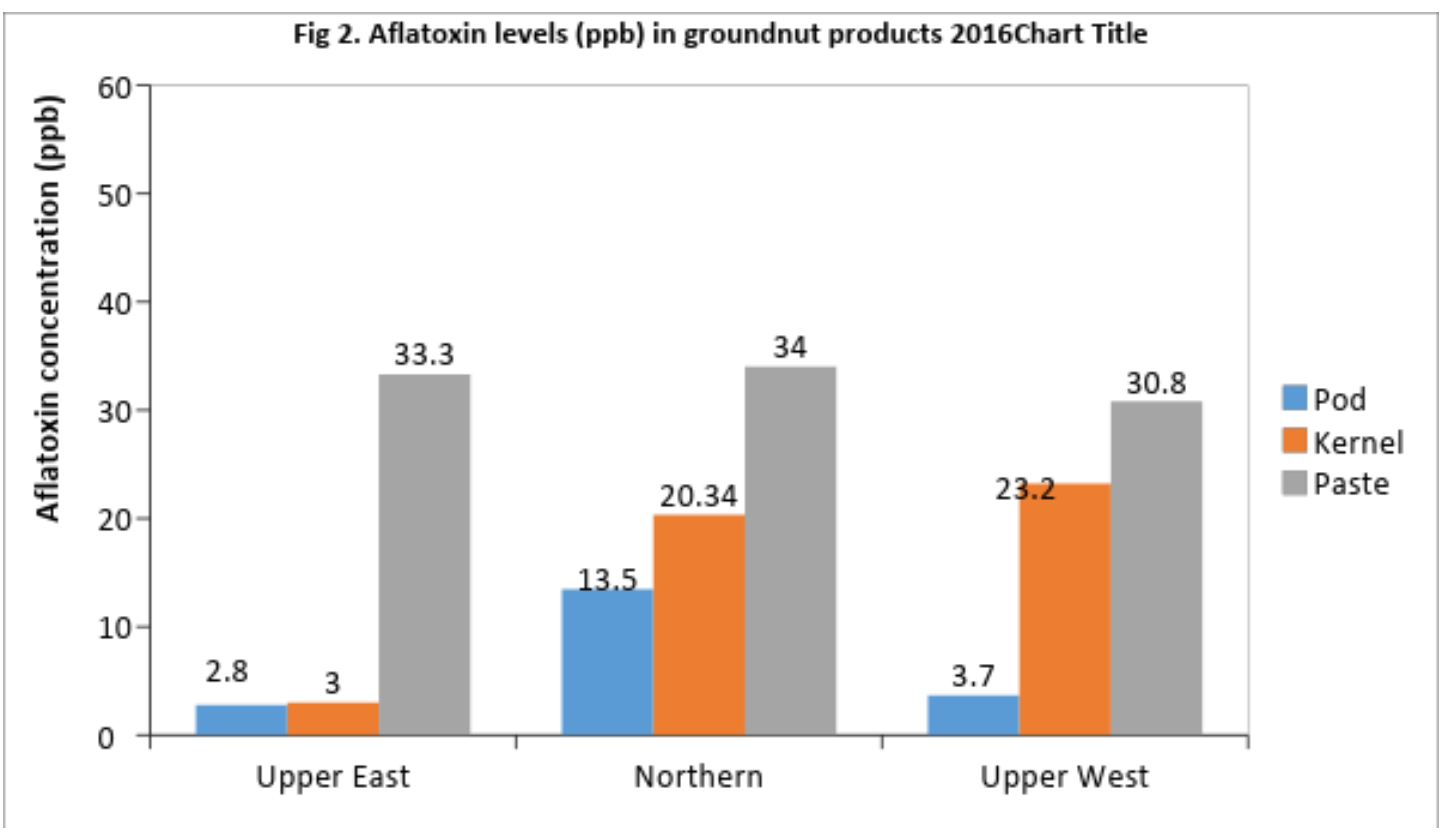

The lower levels of aflatoxin in pod than in kernel samples agree with earlier reports that storing groundnut in pods rather than kernel, minimizes risks of aflatoxin contamination (1.8). Commercial GPs are usually produced from low quality (shrivelled, broken, damaged) grains which are known to be more prone to aflatoxin contamination (Awuah,
2000; Waliyar et al., 2015) and this probably explains the higher levels of aflatoxin in such products. The very high levels of aflatoxin in GPs sampled from markets is a worrying situation that needs redress as most rural families rely on these for the preparation of their household diets. 
In conclusion, our studies clearly showed that improved varieties and agronomic practices can effectively reduce aflatoxin contamination in groundnut production. Most groundnut products sampled from farm households and markets, had aflatoxin levels higher than the EU acceptable limit of $4 \mathrm{ppb}$ and this calls for more intensive sensitization of value chain actors, especially the processors, and rigorous monitoring of groundnut products to minimize the risks of human and livestock poisoning from aflatoxin contamination.

\section{Acknowledgement}

We are grateful to USAID/ICRISAT for funding the studies and to the various partner institutions in Ghana for implementing various activities in the districts.

\section{References}

Angelucci. F., Bazzucchi, A., 2013. Analysis of incentives and disincentives for groundnuts in Ghana. Technical notes series, Monitoring African Food and Agricultural Policies project MAFAP, FAO, Rome, $25 \mathrm{pp}$.

Awuah, R.T., 2000. Aflatoxigenic fungi and aflatoxin contamination of groundnut based products in Ghana: Implications and concerns. In: $\mathrm{R} T$ Awuah and $\mathrm{W}$ $\mathrm{O}$ Ellis (eds): Proceedings of the
National Workshop on Groundnut and Groundnut Aflatoxins, SantasiKumasi, Ghana. Pp. 17-26.

Owusu-Akyaw, M., Mochiah, M.B., GyasiBoakye, S., Asafu-Agyei, J.N. 2014. Integrated Practices to Manage Diseases, Nematodes, Weeds and Arthropod Pests of Groundnut in Ghana. CRI/NCSU. 102 pp.

Tanzubil P.B. 2016. Incidence of arthropod pests and diseases of groundnut (Arachis hypogaea L.) in Northern Ghana. Journal of Entomology and Zoology Studies 4(4): 29-32

Tsigbey, F.K., Brandenburg, R.L, Clottey, V.A. 2003. Peanut production methods in northern Ghana and some disease perspectives. Journal of Agronomy 34(2):36-47.

Waliyar, F., Umeh, V. C., Traore, A., Osiru, M., Ntare, B. R., Diarra, B., Kodio, O., Kumar, K.V., Sudini, H. 2015. Prevalence and distribution of aflatoxin contamination in groundnut (Arachis hypogaea L.) in Mali, West Africa. Crop Protection 70 (5): 1-7.

William, A.M., Shibani, G.F., James, A. D., Sarpong, D.B., 2013. Comprehensive assessment of the peanut value chain for nutrition improvement in Ghana. Final report, September 2013. Global Alliance for Improved Nutrition (GAIN), Tufts University: 102 pp.

\section{How to cite this article:}

Paul B. Tanzubil and Iddrisu Adam. 2019. Incidence and Management of Aflatoxin Contamination in Groundnut (Arachis hypogaea L.) in Northern Ghana. Int.J.Curr.Microbiol.App.Sci. 8(02): 1296-1300. doi: https://doi.org/10.20546/ijcmas.2019.802.151 